\title{
Smart services: The move to customer orientation
}

\author{
Rainer Alt ${ }^{1} \cdot$ Haluk Demirkan ${ }^{2} \cdot$ Jan Fabian Ehmke ${ }^{3} \cdot$ Anne Moen $^{4} \cdot$ Alfred Winter $^{1}$
}

Published online: 23 February 2019

(C) Institute of Applied Informatics at University of Leipzig 2019

Jel classification $\mathrm{L} 22 \cdot \mathrm{L} 8 \cdot \mathrm{O} 14 \cdot \mathrm{D} 26$

\section{Dear readers,}

Today, the attribute "smart" is widely used. Among the examples are smart infrastructures, smart systems, smart cities, smart products or even the smart world (Liu et al. 2019). In a preface to a special issue published in Electronic Markets on smart tourism, the guest editors mentioned that “"'Smart” has become a new buzzword to describe technological, economic and social developments fueled by technologies that rely on sensors, big data, open data, new ways of connectivity and exchange of information (e.g., Internet of Things, RFID, and NFC) as well as abilities to infer and reason." (Gretzel et al. 2015, p. 179). Since then the "buzz" has spread further and as with many buzzwords, their understanding is heterogeneous and differs depending on the background of the authors. For example, many researchers in the domain of smart cities adopt a technological perspective and analyze sensors, interfaces or platform architectures that enable use cases in an urban environment (e.g. Puiu et al. 2016). A view on smart products and the associated topics of cyber-physical systems reveals a more or less similar picture. On the other side, researchers from the information systems discipline bring attention to the increasing capabilities of computers, and how they are increasingly doing things that humans could once do exclusively. In their definition, smart machines are becoming like humans by recognizing voices, processing natural language, learning, and interacting with the physical world through their vision, smell, touch, and other senses, mobility and motor control with advanced artificial intelligence, intelligence augmentation and data (Demirkan

Rainer Alt

rainer.alt@uni-leipzig.de

Leipzig University, Leipzig, Germany

2 University of Washington - Tacoma, Tacoma, WA, USA

3 University of Magdeburg, Magdeburg, Germany

4 University of Oslo, Oslo, Norway et al. 2016; Matzner et al. 2018). They profoundly impat the current organization of business processes as illustrated in muliple examples by Porter and Heppelmann (2015). The present special issue on smart services follows this direction and that of the earlier on smart tourism by considering the interplay of technological, economic and social dimensions.

\section{The (smart) service economy}

The special issue comprises eight papers that cover various aspects of smart services. They show that "smartness" always complements a physical (material) good or an (immaterial) service (Porter and Heppelmann 2015). By the years, the latter have become more important, which is apparent in the development of many economies worldwide. Since the midtwentieth century, service industries account for $63 \%$ of the gross domestic product (GDP) worldwide and clearly dominate the industrial sector $(30 \%)$ as well as the agricultural sector (6.4\%) (CIA 2018). More developed countries, such as North American, Asian and European countries show even higher values for the service sector (70-80\%) and correspondingly lower levels for the industrial (20-25\%) and the agricultural sector $(<1 \%)$. A key characteristic in this shift from industrial to service industries lies in the nature of the product itself: while physical products are manufactured following industrial principles and are then sold to customers, services are immaterial in nature and rely on the interaction between a service provider and a service consumer. The well-known examples of a session with a barber, a bank advisor or a physician, illustrate that services emerge from a pre-configuration of resources, i.e. the ability, the equipment and the facilities to exert a haircut, and are not amenable to production on stock. Instead, services require the presence of a service consumer, i.e. a customer who desires a haircut or a patient that experiences certain pain. Due to the immaterial nature of many services, information technologies (IT) have played an important role in their diffusion. Most recently, researchers and professionals are talking about growth 
of another transformation, which some call "digital transformation." The expectations are high: According to the report "Global digital transformation market" the digital transformation market is projected to grow from US\$ 445.4 bn in 2017 to USD 493.39 bn by 2022 and to US $\$ 2279.4$ bn by 2025 (Reportbuyer 2018).

This development may be seen as service transformation that is being enabled by digital and mostly smart machines (Demirkan et al. 2016). It denotes a revolution of business and organizational activities, processes and models by leveraging the utilization of a mix of digital technologies. Services are the core of almost all successful digital transformations for organizations and these digital technologies become the interactive encounters. The interactive encounter between service provider and service consumer has led to a second characteristic of services. This is the shift from owning to using goods, which has become known as the sharing economy. For example, a service relieves the customer from having to take care of the pre-configuration of the service. For a mobility service, the users only use a vehicle for getting from A to B without having to deal with purchasing or maintaining it. In the literature, the interaction among service providers and the users inherent in the notion of service is also recognized as a service system. It may be defined as "a dynamic value co-creation configuration of resources, including people, organizations, shared information (language, laws, measures, methods), and technology, all connected internally and externally to other service systems by value propositions." (Stoshikja et al. 2016, p. 216). In the marketing literature, the thinking of co-creation has even been extended beyond the mere distinction of physical goods and immaterial services with the service-dominant logic (SDL). SDL "represents a shift from a focus on firm output with some sort of embedded 'goodness' (utility) to a focus on the process of actors reciprocally using their resources [...] with other actors, for mutual benefit - that is, for mutual value creation." (Lusch and Vargo 2019, p. 4).

\section{Role of information technology}

The first paper of this special issue illustrates the aspect of cocreation and states that "these "smart products" enable the cocreation of "smart services" that is based on monitoring, optimization, remote control and autonomous adaptation of products." (Beverungen et al. 2019). The authors argue that service systems are transformed towards smart service systems. As shown in Fig. 1, smart functionalities may enrich or complement physical goods or services. This follows the traditional use of IT in electronic commerce: information about physical products that was attached on paper to the product may be decoupled and made ubiquitously available. Typical examples are electronic data interchange documents or websites for tracking and tracing physical goods. In the same vein, the status on services may be IT-supported. For example, appointments with service providers may be published electronically or the status of a service (e.g. the opening of a bank account) may be monitored. However, the notion of "smartness" goes beyond mere transparency. In particular, the properties of the underlying resource may also be influenced (control) or analyzed. Among others, this refers to activating or deactivating product functions and the generation of usage profiles or simulations. This corresponds to prior research, which conceives "smartness" as the use of technology to enable a "wise and interacting management of service systems' assets, goals" while also "being capable for selfreconfiguration" (Barile and Polese 2010, p. 31).

An overview on the various underlying smart service definitions from contributions in this special issue (see Table 1) illustrates these aspects by referring to the value creation that occurs when service provider and consumer interact (co-creation), to the enhancement of underlying IT-based (smart) products with additional functionalities, to the dynamic aspects that emerge from time and location specificity (context) and, finally, to a more active role of the service consumer (customer orientation).

\section{Strategies for smart services}

Following these "building blocks" of smart services, the articles in this special issue shall be positioned along two dimensions. On the one hand smart services enhance existing products (either physical goods or service) with smart functionality and on the other hand services imply a business model that differs between providers of goods and services and third parties that adopt a mediating role between providers and customers:

- The value base denotes the source of value (Lepak et al. 2007), which may be the product itself, the "intelligence" of this product (smart properties) as well as many instances using this product (crowd properties). As indicated in some contributions, crowd properties may be conceived as additional data that emerges from the collection of data from various instances (or users) of a product. For example, it is known that the autonomous driving skills of smart cars are improved with the availability of a continuous data stream from a large population of these autonomous vehicles. The same applies to a smart mobility service.

- The business model refers to elements, such as the value proposition, the actor structure and the revenue model (Alt and Zimmermann 2014). The provider perspective is included in what has been described 
Fig. 1 Enhancements of products and services

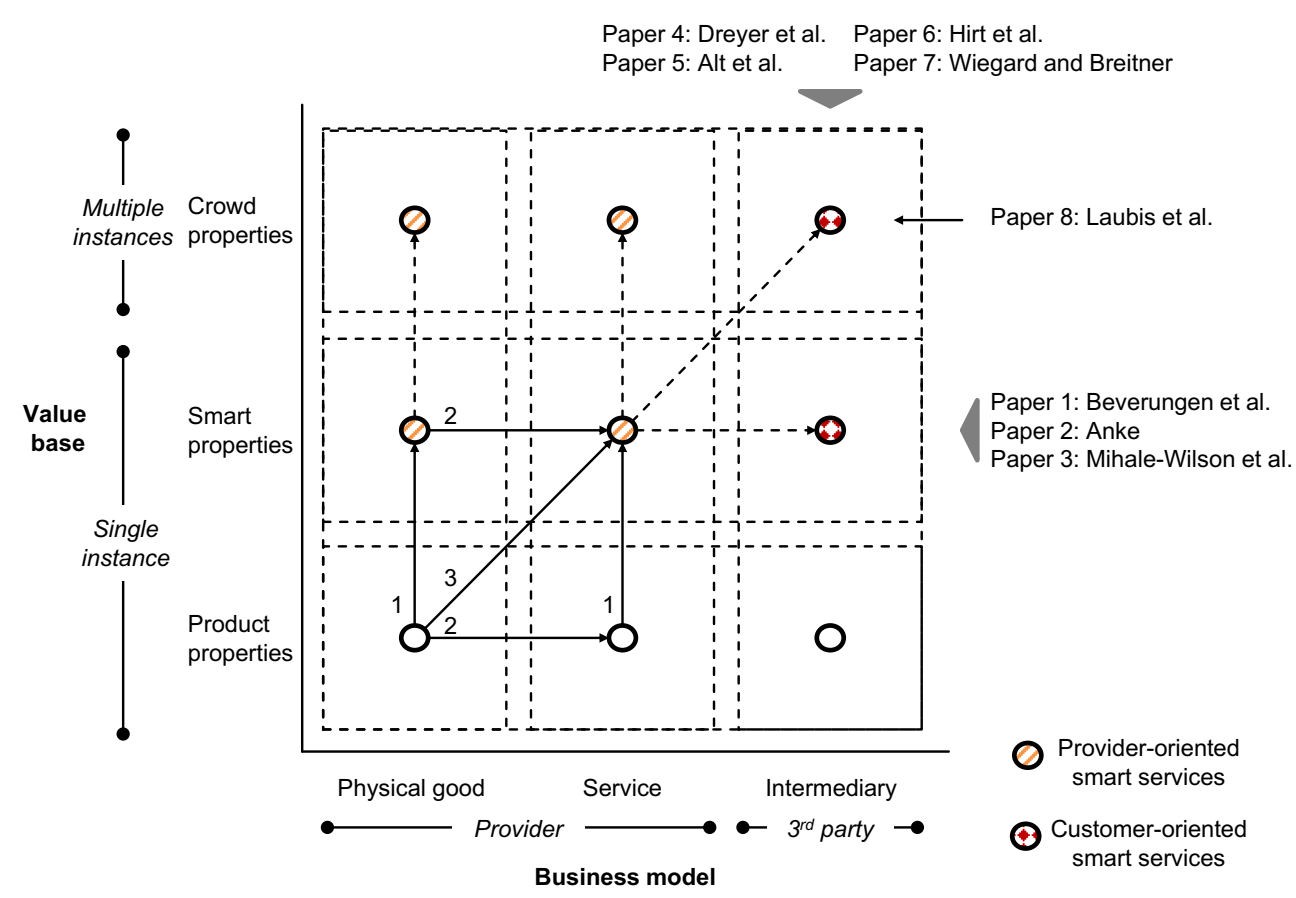

above with the distinction between goods that are sold and subsequently possessed by their users and the usage-based model offered by service providers. The logic of third party services is different since the business model of intermediaries such as dealers or brokers, typically relies on the connection of providers and customers. It leads to the distinction of provider-oriented and customer-oriented smart services.

Combining the two dimensions yields a framework that allows the discussion of various strategies. Arrows indicate examples for possible trajectories between strategic options and how the framework could be applied to explain the strategic intention and the evolution of smart services. As discussed above, arrow 1 describes the emergence of smart products and services and arrow 2 the shift in the underlying business model. In this case, the traditional goods-based model is changing to a service-based model. Revenues are not generated by selling physical products, but by charging the usage of these services. For example, instead of owning a car, users are now members of carsharing, homesharing, officesharing or other mobility services. Of course, physical goods and services may be combined (see Fig. 1 left and middle quadrants in the product property line), which leads to product-service systems (Baines et al. 2007). In case smart

Table 1 Definitions of "smart service" in the special issue papers

\begin{tabular}{ll}
\hline Author(s) & Definition \\
\hline Anke (2019) & $\begin{array}{c}\text { Smart services are service systems, which enable value co-creation between a service provider } \\
\text { and beneficiary through the joint performance of service activities }\end{array}$ \\
Sevart service is the application of specialized competences, through deeds, processes, \\
and performances that are enabled by smart products. Smart service systems are service \\
systems in which smart products are boundary objects that integrate resources and \\
activities of the involved actors for mutual benefit. \\
$\begin{array}{c}\text { Smart services are individual, highly dynamic and quality-based service solutions that are } \\
\text { convenient for the customer, realized with field intelligence and analyses of technology, } \\
\text { environment and social context data (partially in real-time), resulting in co-creating value } \\
\text { between the customer and the provider in all phases from the strategic development to the } \\
\text { improvement of a smart service. } \\
\text { Smart service systems are systems that are designed for self-management and self-reconfiguration } \\
\text { to ensure the provision of a satisfactory service to the participants. } \\
\text { Smart services are a combination of physical and digital value-added services based on smart products } \\
\text { like wearables. }\end{array}$ \\
Laubis et al. (2019) \\
Wiegard and Breitner (2019)
\end{tabular}


properties (i.e. transparency, control, analytics) are present, these may be recognized as smart product service systems (left and middle quadrants in the smart properties line of Fig. 1). Typically, these systems feature a certain complexity since multiple services (e.g. a mobility and a payment service) from various providers have to be combined (Stoshikja et al. 2016, p. 215f). Arrow 3 is interesting since a material good is then replaced by a service. An example is the substitution of physical answering machines with virtual mailbox services.

The right column is different in this respect that an intermediary acts as a broker between the provider and the consumer. Contrary to the left and the middle column in Fig. 1, the perspective is not from a single provider of a good or service, but from an actor that provides an overview on multiple actors. Often, this occurs to increase the market transparency and to reduce the complexity for buyers (Rose 1999, p. 65). A key element of this mediation also represents the translation of domain-specific terminology and contexts into a language that customers understand who are unfamiliar with these domains (Alt 2016). In this sense, intermediaries are "agents" of customers and shift the perspective from providers to customers. Smart services offered by such intermediaries could thus be referred to as more customer-oriented smart services (see dotted lines to right column in Fig. 1). They enable customers or patients to not only retrieve and contract relevant offerings, but also to configure them according to their individual preferences. However, the bundling and tracking of complex service systems across service providers, such as banks, hospitals or transportation companies, is still a challenging task and often requires substantial coordination on behalf of the customer today.

\section{Special issue papers}

This was the initial idea of this special issue. It aims to advance research in the smart service domain and to use "smartness" for enabling a customer-oriented outside-in perspective. It follows the intention of service science, which posits that "smart service systems serve their clients better and develop enhanced opportunities for win-win situations that again result in increased value co-creation for both service providers and clients" (Beverungen et al. 2019). In order for service providers to be successful in the long run, they need to co-design their services for customer orientation, i.e. following the idea of one-to-one marketing towards a segment of one. We are already experiencing examples, such as Google Now, Amazon Alexa, Microsoft Cortana and Apple Siri, which use the "wisdom of the crowd" and are added to existing services (see dotted lines in the upper line of Fig. 1). This special issue seeks research on the concepts, solutions and findings that help in advancing service thinking regarding more customer experience and empowerment as well as value co-creation. The seven research papers and one position paper of this special issue contribute to the domain of smart services from different perspectives.

The initial set of three papers may be attributed to advancing the understanding of smart services. The first is titled "Conceptualizing smart service systems" and delivers valuable groundwork for smart services. The authors Daniel Beverungen, Oliver Müller, Martin Matzner, Jan Mendling and Jan vom Brocke substantiate the understanding of smart services and elaborate on the characteristics as well as the implications of smart service systems (Beverungen et al. 2019). Five case studies serve to illustrate the conceptual framework, which may be conceived as a generalized architecture of a smart service system. The second and the third paper are helpful when designing smart services. Titled "Design-integrated financial assessment of smart services", the research from Jürgen Anke recognizes that smart services are configurations of various services (Anke 2019). By nature they are complex since the services may originate from various disciplines, which requires that technological, organizational and strategic skills are aligned in a smart service project. To structure the necessary steps a meta-model is developed that aids in assessing the financial impact of smart services already in the early design stages. A prototype serves to validate the model in a lab experiment. The paper by Andreea Cristina Mihale-Wilson, Jan Zibuschka and Oliver Hinz investigates which features should be supported by in-vehicle assistant services. In their research they analyze the user preferences and the willingness to pay for in-vehicle assistance services based on an empirical study with almost 300 participants from Germany (Mihale-Wilson et al. 2019). The results yield valuable insights regarding the optimal design of these services. Another set of four papers may be assigned to understanding how smart services could support the move to customer orientation:

- The fourth paper comprises a literature review on how smart services enable the customer perspective and sheds light on the research directions that may be observed in the literature. The authors Sonja Dreyer, Daniel Olivotti, Benedikt Lebek and Michael H. Breitner identify a total of 13 topics across five phases of the smart service lifecycle (Dreyer et al. 2019). The results reveal that economic aspects and the role of the customer receive only inferior attention. The authors also point at machine learning and knowledge management as promising fields for future research.

- This leads to the fifth contribution, which is a position paper introducing the concept of customer inducement. In their position paper the authors Rainer Alt, Jan Fabian Ehmke, Reinhold Haux, Tino Henke, Dirk Christian Mattfeld, Andreas Oberweis, Barbara Paech and Alfred Winter complement the research paper from Dreyer et al. (2019) and argue that current approaches to customer orientation are 
still largely provider-oriented (Alt et al. 2019). They present the concept of customer-induced service orchestration that aims at empowering customers to bundle service from various providers along entire customer journeys. Examples for the latter are travel plans in the mobility domain or treatment plans in the healthcare sector. Four requirements are formulated that are necessary to enable services that allow for customer-induced service orchestration.

- Another paper besides the position paper that applies machine learning is presented by Robin Hirt, Niklas Kühl and Gerhard Satzger. Titled "Cognitive Computing for Customer Profiling", the authors apply machine learning to customer profiling and propose a meta classification for gender prediction that is based on micro blogs (Hirt et al. 2019). The prototype is used in an experimental setting and proves beneficial in understanding customer needs and in improving the offering of individualized services.

- The seventh article shows an example for smart services in healthcare and includes a risk-benefit-analysis for socalled pay-as-you-live services, which are based on wearable technologies. The authors Rouven-B. Wiegard and Michael H. Breitner investigate the adoption of these smart services, in particular, the perceived benefits and the privacy risks, from the customer's perspective (Wiegard and Breitner 2019). The insights are based on an online survey and the test of ten hypotheses reveals that privacy is a key concern of customers and, thus, needs to be addressed by providers.

Finally, the example for an intermediary business model based on crowd properties is described by Kevin Laubis, Marcel Konstantinov, Viliam Simko, Alexander Gröschel and Christof Weinhardt. They present a crowdsensing-based road condition monitoring service that complements existing professional services from specialized engineering companies and enables an efficient road monitoring on a broader scale (Laubis et al. 2019). The service is based on sensors that are widespread in vehicles as well as in smartphones. Several services build on these data services, such as analytics, business, and finally, smart services. The latter create the foundation of an intermediary business model that is also validated in this design-oriented article.

As we have seen in this special issue, understanding customer orientation is the key for today's exponentially growing service transformation and service economy with smart services. While the papers here provide cogent examples of smart services for customer orientation, the discipline and its applications are growing rapidly. Customer orientation, value co-creation and service science are transdisciplinary in nature and focus on people, processes and technologies that can implement autonomous intelligence to various applications such as autonomous vehicles, medical diagnostics, machine vision, translation, employee performance evaluations, planning and scheduling, marketing analytics and others too numerous to mention here. It is our intent that the papers presented here will motivate the reader's journey of discovery on what constitutes one of the most important topics in the field of electronic markets.

Acknowledgements We know the importance of having to start somewhere to get new ideas moving, and of finding the appropriate collaborators to make initial steps and advances in new knowledge possible. We thank the editors of Electronic Markets for the vision they shared with us and for getting the discussion rolling. This issue received several submissions which underwent a two/three-cycle "review and revise" process before we were able to select the final articles. We would especially like to acknowledge the anonymous reviewers who so generously offered their time, effort, and helpful insights for us to make these hard choices and for helping us in developing the final "product". Finally, we thank the authors whose work was accepted and those whose research we were unable to publish in this edition. We hope the reviewers' comments will strengthen their future success. We hope you enjoy reading this special issue.

The guest editors

Publisher's note Springer Nature remains neutral with regard to jurisdictional claims in published maps and institutional affiliations.

\section{References}

Alt, R. (2016). Electronic markets on customer-orientation. Electronic Markets, 26(3), 195-198. https://doi.org/10.1007/s12525-016$0229-\mathrm{y}$.

Alt, R., \& Zimmermann, H.-D. (2014). Editorial 24/4: Electronic markets and business models. Electronic Markets, 24(4), 231-234. https:// doi.org/10.1007/s12525-014-0178-2.

Alt, R., Ehmke, J. F., Haux, R., Henke, T., Mattfeld, D. C., Oberweis, A., Paech, B., \& Winter, A. (2019). Towards customer-induced service orchestration - requirements for the next step of customer orientation. Electronic Markets, 29(1), in press.

Anke, J. (2019). Design-integrated financial assessment of smart services. Electronic Markets, 29(1). https://doi.org/10.1007/s12525-0180300-y.

Baines, T. S., et al. (2007). State-of-the-art in product-service systems. Journal of Engineering Manufacture, 221, 1543-1552. https://doi. org/10.1243/09544054JEM858.

Barile, S., \& Polese, F. (2010). Smart service systems and viable service systems: Applying systems theory to service science. Service Science, 2(1-2), 21-40. https://doi.org/10.1287/serv.2.1_2.21.

Beverungen, D., Müller, O., Matzner, M., Mendling, J., \& vom Brocke, J. (2019). Conceptualizing smart service systems. Electronic Markets, 29(1). https://doi.org/10.1007/s12525-017-0270-5.

CIA. (2018). The CIA World Factbook 2018-2019. New York: Skyhorse.

Demirkan, H., Spohrer, J., \& Welser, J. J. (2016). Digital innovation and strategic transformation. IT Professional, 18(6), 14-18. https://doi. org/10.1109/MITP.2016.115.

Dreyer, S., Olivotti, D., Lebek, B., \& Breitner, M. H. (2019). Focusing the customer through smart services: A literature review. Electronic Markets, 29(1). https://doi.org/10.1007/s12525-019-00328-z.

Gretzel, U., Sigala, M., Xiang, Z., \& Koo, C. (2015). Smart tourism: Foundations and developments. Electronic Markets, 25(3), 179188. https://doi.org/10.1007/s12525-015-0196-8. 
Hirt, R., Kühl, N., \& Satzger, G. (2019). Cognitive computing for customer profiling: Meta classification for gender prediction. Electronic Markets, 29(1), in press.

Laubis, K., Konstantinov, M., Simko, V., Gröschel, A., \& Weinhardt, C. (2019). Enabling crowdsensing-based road condition monitoring service by intermediary. Electronic Markets, 29(1). https://doi.org/ 10.1007/s12525-018-0292-7.

Lepak, D. P., Smith, K. G., \& Taylor, M. S. (2007). Introduction to special topic forum: Value creation and value capture: A multilevel perspective. The Academy of Management Review, 32(1), 180-194. https:// doi.org/10.5465/amr.2007.23464011.

Liu, H., et al. (2019). A review of the smart world. In Future generation computer systems. https://doi.org/10.1016/j.future.2017.09.010.

Lusch, R. F., \& Vargo, S. L. (2019). An overview of service-dominant logic. In S. L. Vargo \& R. F. Lusch (Eds.), The SAGE handbook on service-dominant logic (pp. 3-21). Sage: London etc.

Matzner, M., Büttgen, M., Demirkan, H., Spohrer, J., Alter, S., Fritzsche, A., Ng, I. C. L., Jonas, J. M., Martinez, V., Möslein, K. M., \& Neely, A. (2018). Digital transformation in service management. Journal of Service Management Research, 2(2), 3-21. https://doi.org/10. 15358/2511-8676-2018-2-3.

Mihale-Wilson, A. C., Zibuschka, J., \& Hinz, O. (2019). User preferences and willingness to pay for in-vehicle assistance. Electronic Markets, 29(1). https://doi.org/10.1007/s12525-019-00330-5.
Porter, M. E., \& Heppelmann, J. E. (2015). How smart, connected products are transforming companies. Harvard Business Review, 93(10), 96-11.

Puiu, D., Barnaghi, P., Tönjes, R., Kümper, D., Ali, M. I., Mileo, A., Parreira, J. X., Fischer, M., Kolozali, S., Farajidavar, N., Gao, F., Iggena, T., Pham, T.-L., Nechifor, C.-S., Puschmann, D., \& Fernandes, J. (2016). CityPulse: Large scale data analytics framework for smart cities. IEEE Access, 4, 1086-1108. https://doi.org/ 10.1109/ACCESS.2016.2541999.

Reportbuyer (2018). Digital transformation market to 2025 - global analysis and forecasts. Reportbuyer, May 2018. https://www. reportbuyer.com/product/5436760. Accessed 21 Jan 2019.

Rose, F. (1999). The economics, concept, and design of information intermediaries. Physica: Heidelberg. https://doi.org/10.1007/978-3642-99805-8.

Stoshikja, M., Kryvinskaa, N., \& Strauss, C. (2016). Service systems and service innovation: Two pillars of service science. Procedia Computer Science, 83, 212-220. https://doi.org/10.1016/j.procs. 2016.04.118.

Wiegard, R.-B., \& Breitner, M. H. (2019). Smart services in healthcare: A risk-benefit-analysis of pay-as-you-live services from customer perspective in Germany. Electronic Markets, 29(1). https://doi.org/10. 1007/s12525-017-0274-1. 